\title{
Bandwagons and Quiet Corners in Regulatory Governance
}

On regulation-specific and institutional drivers of stakeholder engagement

\section{Caelesta Braun, Adrià Albareda, Bert Fraussen and Moritz Müller}

\section{(2) OpenEdition}

\section{Journals}

Electronic version

URL: http://journals.openedition.org/irpp/1151

DOI: 10.4000/irpp.1151

ISSN: 2706-6274

\section{Publisher}

International Public Policy Association

\section{Printed version}

Date of publication: 1 September 2020

Number of pages: 209-232

ISSN: 2679-3873

\section{Electronic reference}

Caelesta Braun, Adrià Albareda, Bert Fraussen and Moritz Müller, "Bandwagons and Quiet Corners in Regulatory Governance", International Review of Public Policy [Online], 2:2 | 2020, Online since 01 September 2020, connection on 29 January 2021. URL: http://journals.openedition.org/irpp/1151 ; DOl: https://doi.org/10.4000/irpp.1151

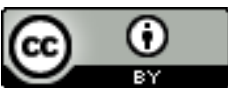

International Review of Public Policy is licensed under a Creative Commons Attribution 4.0 International. 


\section{Bandwagons and Quiet Corners in Regulatory Governance On regulation-specific and institutional drivers of stakeholder engagement}

\section{Caelesta Braun}

Professor at the Institute of Public Administration, Leiden University

\section{Adrià Albareda}

Assistant Professor at the Department of Public Administration and Sociology - Erasmus University Rotterdam; and Researcher at the Institute of Public Administration, Leiden University

\section{Bert Fraussen}

Assistant Professor at the Institute of Public Administration, Leiden University

\section{Moritz Müller}

PhD candidate at the Institute of Public Administration, Leiden University

\section{Abstract}

Stakeholder engagement is often considered an essential component of regulatory policymaking and governance. Our main aim in this paper is to explain variation in stakeholder engagement across regulatory trajectories. More specifically we aim to assess why some regulatory policymaking processes attract a larger and more diverse set of stakeholders, while others attract much smaller and more homogenous regulatory crowds. We build on a newly established dataset of primary data regarding stakeholder engagement in EU regulatory governance to test our assumptions. We find that both the salience and the number of different consultation instruments affect the density and diversity of stakeholder engagement, whereas the complexity of regulations seems to mainly affect the density of stakeholder engagement. The combination of both institutional and regulation-specific drivers of stakeholder engagement in regulatory governance yields relevant implications for the study of responsive regulation and the role stakeholders can fulfill in regulatory decision-making.

\section{Keywords}

stakeholder, engagement, regulatory governance, interest representation 


\section{Introduction}

Stakeholder engagement has become a prominent principle in the study and practice of (supra) national regulatory policymaking and governance. The OECD considers stakeholder engagement in regulatory governance a good governance practice: "The central objective of regulatory policy - ensuring that regulations are designed and implemented in the public interest - can only be achieved with help from those concerned by regulations - the stakeholders" (OECD 2016 , p. 3). The importance of stakeholder engagement in regulatory governance has long been identified in the literature on regulatory governance (Ayres and Braithwaite 1992; Black 2003; Coglianese, Zeckhauser and Parson 2004) and more recently through the regulatory intermediary framework, which theorizes the different roles stakeholders can fulfill in regulatory governance. Engaging stakeholders will benefit the regulatory process throughout the different stages, including both 'downstream' roles (monitoring and compliance) and 'upstream' roles such as providing expertise and in advisory functions (Abbott and Snidal 2013; Abbott, LeviFaur and Snidal 2017; Brès, Mena and Salles-Djelic 2019; Martinez, Verbruggen and Fearne 2013). In addition, stakeholder engagement has been related to the effectiveness and legitimacy of governance (e.g. Bingham, Nabatchi and O'Leary 2005) and is often considered critical to both collect necessary policy input and ensure alignment between regulations and the public interest (European Commission 2017; OECD 2012).

We will contribute to the study of stakeholder engagement in (supra)national regulatory governance by explaining the number (density) and type (diversity) of stakeholders that engage with policymakers in regulatory governance, defined as the process by which multiple public and private stakeholders participate to advance regulations (Gray and Lowery 1996; Lowery et al. 2015; see also Arras 2017; Berkhout et al 2015; Halpin and Jordan 2012; Leech et al 2005). Our main aim in this paper is therefore to assess why some supranational regulatory processes attract a large and diverse set of stakeholders, while others attract a much smaller and more homogenous set of stakeholders. Our analysis and findings make a twofold contribution to the study of stakeholder engagement in (supra)national regulatory governance. First, we contribute by developing an analytical framework which we empirically test to demonstrate how contextual factors affect stakeholder engagement in regulatory governance. Second, our findings indicate that the future models of stakeholder engagement in regulatory governance can be better specified by explicitly including regulation-specific and institutional explanatory factors.

In the remainder of this paper, we first discuss the importance of examining stakeholder engagement for the study of (supra)national regulatory governance. We then introduce our theoretical framework of key regulation-specific and institutional factors to explain variance in stakeholder engagement. More specifically, we focus on regulation-specific (i.e., salience and complexity) and institutional-level characteristics (i.e., consultation instruments and administrative capacity) to explain why stakeholder engagement varies across European Union (EU) regulations. The EU is considered a typical case of the regulatory state (Majone 1997) and has one of the most extensive and transparent consultation regimes. Specifically, we focus on how the European Commission involves stakeholders in the regulatory-formulation stage. Being one of the most elaborate and ambitious consultative regimes (Bunea 2017, p. 47), the EU stands as a relevant case to examine the determinants of stakeholder engagement in regulatory processes. To test our assumptions, we drew on novel datasets of stakeholder engagement in EU regulatory governance: a regulatory database consisting of 47 regulations passed by the EU in the period 2015-2016, containing an extensive analysis of regulatory characteristics, and 
a stakeholder database that comprises key organizational features of 2,656 stakeholders that mobilized for these regulations. We focused on a two-year period as this enabled us to collect data on regulations in a variety of policy domains, as well as other quantitative (e.g. media data) and qualitative data through interviews with public officials and stakeholders.

Our main finding is that salience and the specific usage of consultation instruments explain both the density and diversity of stakeholder engagement, whereas complexity only seems to affect the density of stakeholder engagement. We did not find significant effects of administrative capacity on both the density and diversity of stakeholder engagement. Our analysis suggests that for better explanations of the effect of stakeholder engagement in regulatory governance, regulation-specific characteristics as well as institutional arrangements are important conditions to consider.

\section{Explaining stakeholder engagement in regulatory governance}

An important explanation within the literature on interest representation and particularly relevant for examining stakeholder engagement in supranational regulatory governance concerns the type and level of government activities. Such 'demand-side' factors are generally positively associated with the type and number of stakeholders that engage with the decision-making process (Gray Lowery and Benz 2013; Halpin, Fraussen and Nownes 2018; Klüver and Zeidler 2018; Leech et al 2005; Lowery and Gray 2004, Lowery et al 2004). In the same vein, we expect such demand side factors, i.e. both institutional and regulation-specific contextual factors, to affect stakeholder engagement in regulatory governance.

More precisely, we develop a framework to systematically assess sources of variation in the number (density) and type (diversity) of stakeholders involved in regulatory governance. We refer to stakeholders collectively as the set of any type of organization that has a stake in particular regulatory policy issues, such as firms, business associations, NGOs, civil society organizations and public authorities. In the context of this paper, density refers to the number of stakeholders that mobilized around a specific regulation. Previous research has demonstrated that density varies considerably across policy sectors and policy issues (e.g. Berkhout et al 2015; Klüver and Zeidler 2018; Messer, Berkhout and Lowery 2011), with typically a few issues generating high levels of stakeholder mobilization, and many issues receiving very little attention from stakeholders. Whereas the former pattern has been described as a "bandwagon effect", as more stakeholders jump on board when an issue starts moving, the latter has been referred to as "quiet corners" (Baumgartner and Leech 2001; Halpin 2011; see also Culpepper 2010, 248), for which only a few stakeholders become engaged. Clearly, variation in the density of stakeholders will strongly affect policymaking dynamics, and consequently also affect the possible role and impact of stakeholders (e.g. Breunig and Koski 2018; Hanegraaff, Beyers and Braun 2011). Rather than the sheer number of mobilized actors, diversity refers to the variety of substantive interests that engage with policymakers, often conceptualized as the presence of different organizational types or models (e.g. Lowery, Gray and Fellowes 2005; Minkoff, Aisenbrey and Agnone 2008). Diversity is at least equally relevant as density, as it is assumed to affect the variety in perspectives, voices and information that get heard by policymakers (Berkhout, Hanegraaff and Braun 2017; Beyers and Arras 2019; Pedersen, Halpin and Rasmussen 2015; Rasmussen and Carroll 2014).

Density and diversity are related, yet not in a simple linear way. That is, the involvement of more stakeholders does not necessarily result in a greater diversity among engaged stakeholders. Research has shown that both population dynamics (the number and type of stakeholders 
that are already mobilized) and institutional factors affect both density and diversity in related yet distinct ways (Lowery et al 2005; Lowery and Gray 2016). Understanding how regulationspecific and institutional contextual factors affect both the density and diversity of stakeholder engagement across regulatory processes helps to better specify models of stakeholder engagement. Moreover, it improves our understanding of variation in the responsiveness or biased nature characterizing regulatory processes, as well as the intermediary role stakeholders can potentially fulfill in the regulatory process. We focus on selected regulation-specific characteristics, including salience and complexity, as such issue-characteristics are generally considered important to take into account when explaining stakeholder engagement (Beyers, Dür and Wonka 2018). In addition, institutional factors have been shown to affect stakeholder engagement as well, and both consultation arrangements (Fraussen, Albareda and Braun 2020; Halpin and Fraussen 2017; Pedersen et al. 2015; Van Ballaert 2015) and administrative capacity (Baekgaard, Mortensen and Seeberg 2018; Bark and Bell 2019) are particularly relevant for explaining stakeholder engagement in regulatory governance. In the next section, we explain these regulation-specific and institutional characteristics in more detail, and formulate hypotheses considering their effect on the density and diversity of stakeholder engagement in regulatory governance.

\section{Hypotheses}

First, as regards regulation-specific factors, we expect that the salience of a regulation, defined here as the relative political attention some specific regulatory issue gains compared to other regulatory issues, affects the size and kind of regulatory mobilization (Klüver, Braun and Beyers 2015). Salient regulations are more visible to potentially interested actors and constituents, which is expected to foster the mobilization not only of those actors that normally mobilize, but also of those who represent diffuse interests - thus increasing the density and the diversity of stakeholder engagement (De Bruycker, Berkhout and Hanegraaff 2019). Previous research has demonstrated that as legislative proposals increase in salience, they become more multidimensional and thus speak to multiple audiences. In such cases, a larger number and often more diverse set of stakeholders will face greater incentives to mobilize and become politically active (Baumgartner et. al 2009; Baumgartner and Mahoney 2008; Hanegraaff and Berkhout 2018; Klüver et al. 2015; Schattschneider 1960). We expect a similar dynamic of conflict expansion and the mobilization of a larger (denser) and more diverse set of stakeholders to apply to regulations.

H1: The more salient a regulation, the higher the levels of density and diversity characterizing stakeholder mobilization.

Second, we expect that the level of complexity of a regulation affects the size and kind of stakeholder mobilization. In the case of regulatory governance, the direction of this relationship is less clear-cut than the anticipated effect of salience for stakeholder engagement during the legislative phase. Complexity is defined as the 'degree to which a given policy problem is difficult to analyze, understand or solve' (Klüver 2013: 58). On the one hand, higher complexity is expected to result in a negative relationship with the quantity and type of stakeholder mobilization, as fewer stakeholders will be capable of offering relevant policy goods and hence have fewer incentives to mobilize (Bouwen 2004; Braun 2012; Klüver et al 2015; ). At the same time, in regulatory governance, commonly associated with expert engagement (see Majone 1997), such a negative relationship might be less outspoken or even be absent given the significant prevalence of experts in the process. So, while we expect an effect of regulatory complexity, at this point we have no concrete assumption regarding the direction of this effect. 
H2: The level of complexity characterizing a regulation will affect the levels of density and diversity characterizing stakeholder mobilization.

In addition to regulation-specific characteristics, we also expect institutional factors to affect the density and diversity of stakeholder mobilization. Consultation tools vary in their degree of openness and hence shape the number and type of stakeholders they filter into the policy system (Pedersen et al. 2015; see also Bunea 2017; Rasmussen and Carroll 2013; Van Ballaert 2017). In EU regulatory governance, many approaches involve a combination of open and closed consultation tools, such as online consultation, advisory committees, expert groups and workshops (see Fraussen et al. 2020 for a more detailed discussion). Our assumption is that as more tools are being applied, both the number and diversity of stakeholders will increase.

H3: The more consultation tools have been applied, the higher the levels of density and diversity characterizing stakeholder mobilization.

Furthermore, studies of stakeholder engagement at the EU-level have demonstrated variance of stakeholder mobilization patterns within specific EU institutions, for instance across different Directorate-Generals, as well as inter-institutional variation in stakeholder mobilization, such as the European Commission versus European Parliament, because of the varying informational demand by either distinct units of a particular public institution or across distinct public institutions (Broscheid and Coen 2003; Coen and Katsaitis 2013; 2017; Princen and Kerremans 2008; Rasmussen and Carroll 2013). We focus on how the administrative capacity of public institutions, defined as "the ability to perform functions, solve problems and set and achieve objectives” (OECD 2003, p 5), affects stakeholder engagement in regulatory processes. More specifically, we focus on one particular dimension of administrative capacity, namely the human resources of public agencies (see Berkhout et al. 2015 for a similar approach). On the one hand, higher administrative capacities might result in a lower number and type of stakeholders (Berkhout et al. 2015; Bouwen 2004; Coen and Katsaitis 2013), the assumption being that higher administrative capacity implies more internal know-how and policy expertise, which reduces the need for information provided by stakeholders (Baekgaard et al. 2018). On the other hand, these higher administrative capacities might also improve the ability of public institutions to engage with a wider set of stakeholders, either to collect more relevant expertise or to ensure broader societal legitimacy (Thomson and Perry 2006). As both expectations appear plausible, we posit no directional effect but a general hypothesis regarding the effect of institutional administrative capacities.

H4: Variation in administrative capacities across Directorate-Generals will affect the levels of density and diversity characterizing stakeholder mobilization.

\section{Design}

The strong emphasis on regulatory governance in the EU and its Member States as well as the general demand for interest representation and inter- and intra-institutional variation of interest representation in the EU, render it a highly relevant case to study the (variation of) the density and diversity of stakeholder engagement in supranational regulatory governance. First of all, the EU's nature as a regulatory state (Majone 1997) renders it a relevant case for an assessment of stakeholder engagement in supranational regulatory governance, also considering that most regulation in EU Member States nowadays originates at the EU-level or at the very least from the interplay between national and EU-level governance. Second, as in other national political systems, we have witnessed a positive correlation between government activity and interest group mobilization in EU governance more generally (Berkhout and Lowery 
2010; Coen and Richardson 2009, Coen and Katsaitis 2013; 2017; Princen and Kerremans 2008; Wonka et al 2010). In addition, multiple studies test institutional factors as explanatory variables for stakeholder mobilization in the EU (Broscheid and Coen 2003; Coen and Katsaitis 2013; 2017; Princen and Kerremans 2008; Rasmussen and Carroll 2013), or more directly examine demand-side effects as part of population ecology models of interest mobilization. These studies have shown a significant effect of demand-side factors for stakeholder engagement at the EU level as well (Berkhout et al 2015). In sum, the nature of the EU as a regulatory state and general significant stakeholder engagement warrant a study of stakeholder engagement in regulatory governance. Specifically, we focus on the European Commission, as the EU institution with the exclusive right to initiate regulations. During the policy-formulation stage, that is, before the Commission publishes a regulatory proposal that will then go to the European Parliament and the Council of the EU, Commission officials reach out and interact with stakeholders through different consultation mechanisms to obtain political and expert information about the regulatory issue under discussion.

To test our hypotheses regarding stakeholder engagement in EU regulatory governance, we constructed two datasets. First, we constructed a regulatory database including characteristics of specific regulatory proposals to facilitate the study of regulation-specific characteristics. These proposals were selected based on a full overview of EU legislative output in the period 2015-2016 in the context of a larger research project on stakeholder engagement in supranational regulatory governance led by one of the authors. We first selected all output that followed the Ordinary Legislative Procedure (OLP) and downloaded the 127 legislations through Euro-Lex. We opted for legislation following the OLP as it is the current standard decision-making procedure for adopting EU legislation (European Union, 2007) and allows us to control for non-equivalent decision-making procedures. To select the regulatory proposals from this full list of OLP output, we define regulation as the intentional intervention in the activities of a target population, following Koop and Lodge (2017, p. 95-108). For our study, we consider interventions to be of a direct and/or indirect nature, the activities can be economic and/or non-economic, the regulatee may equally be a public-sector or private-sector actor, and we refine our analyses to public-sector regulators. While the majority of the cases in our regulatory database are actual regulations, we also included legislative cases with a strong regulatory dimension. Additionally, to account for variation across policy areas (Van Ballaert 2017), we examine six different policy areas in which the EU has exclusive or shared competences with the Member States: (1) Finance, banking, pensions, securities, insurances; (2) State aids, commercial policies; (3) Health; (4) Sustainability, energy, environment; (5) Transport, telecommunications; (6) Agriculture and fisheries. As a consequence, our dataset excludes cases that were exclusively distributional in nature $(n=10)$, centered on EU agency functioning or EU internal matters $(n=8)$ could not be classified in any of the six policy domains of interest for the study $(n=36)$ and codifications of previous regulations $(n=9)$. Out of the 64 remaining regulations, our analysis of the density and diversity of stakeholder engagement in regulatory governance focuses on the 47 regulations for which certain types of formal consultation tools have been employed by the European Commission.

Our second dataset includes the stakeholders that were involved in the 47 regulations that had some sort of formal consultation tools in place, including open (online) consultations, conferences, public hearings and events, workshops, meetings and seminars, expert groups of the Commission and direct meetings with Commission officials (European Commission 2017). To obtain a complete list of stakeholders, we consulted the Commission's proposals, available consultation documents, and impact assessments. As we aimed to obtain as comprehensive a 
picture of stakeholder engagement as possible, we also reviewed other official documents, EU websites, register of expert groups. Furthermore, when the list of stakeholders participating in a particular type of consultation could not be identified via these publicly available sources, we contacted the responsible DG to request the list of stakeholders involved. Combining all these approaches, we identified 2,656 stakeholders, including firms and institutions, but excluding private citizens and anonymous responses to the Commission's consultations. We coded each identified stakeholder following a well-established method in recent interest group studies (Berkhout et al. 2017; 2018; Bernhagen et al. 2016; Beyers et al. 2014). Relying on publicly available data from different organization's websites, human coders identified several key features of the 2,656 stakeholders, including type of group, level of mobilization, country of origin, policy focus, and nature of membership (if applicable).

\section{Dependent variables: density and diversity}

The dependent variables of our analysis include the density and diversity of the 2.656 stakeholders engaged in the set of 47 regulations. These variables are measured by examining the type and number of interest groups involved via consultation tools for the regulations for which consultation tools were employed. Density is measured as the count of the absolute number of stakeholders involved in each regulation and ranges from 1 to 341 groups per regulation. Our measure of diversity of each regulation is the Shannon-normalized index based on a 10-category classification (citizen groups, trade unions, professional associations, business associations, firms, research institutes, institutions, national authorities, EU authorities, and others (including courts, foreign public authorities, and international organizations)). ${ }^{1}$ This coding scheme treats professional associations, business associations and individual firms as distinct stakeholders to allow for the idea of business pluralism (Eising 2007; see also Pagliari and Young 2016). Similar to the Herfindahl-Hirschman Index and other diversity indices, the Shannon index summarizes the diversity of a population (in our case all actors involved in a regulation) in which each member (i.e., stakeholder) belongs to a unique group (i.e., actor type). As shown by Boydstun et al. (2014), Shannon's H and its normalized form minimize the danger of spurious findings that could result from less sensitive Herfindahl measures. We use the normalized form (divide Shannon- $\mathrm{H}$ by the natural log of the total number of actor types) to transform the final output into a value between 0 and 1 for easier comparability (see Boydstun et al 2014). ${ }^{2}$

\section{Independent and control variables}

Our first set of independent variables concerns the regulation-specific characteristics. The first characteristic considered is salience of the regulation, which, as discussed by Beyers et al. (2017), can be captured in different ways. We focus here on the degree of attention that a regulation attracted in the media. Thus, salience is calculated by counting the number of relevant

1 - We conducted an inter-coder reliability test for a randomly selected set of 100 observations from the complete sample list of stakeholders collected. Two coders independently coded six variables for these 100 observations. The Krippendorff's inter-coder reliability test for variable used to construct diversity measures (i.e., actor type) was $\alpha=0.833$, which confirms the reliability of the data (Krippendorff 2004).

2 - Normalized Shannon's $H=\frac{-\sum^{\mathrm{n}}-1\left(p\left(x_{1}\right)\right)+\operatorname{In} p\left(x_{1}\right)}{\operatorname{In}(N)}$ where:

xi represents an item (i.e. each actor type);

$\mathrm{p}(\mathrm{xi})$ is the proportion of total attention the item receives (i.e. relative proportion of involvement of each actor type); $\ln \mathrm{p}(\mathrm{xi})$ is the natural $\log$ of the proportion of attention the item receives;

$\ln (\mathrm{N})$ is the natural log of the total number of items (i.e. total number of actor types). 
articles published in five EU-wide outlets (De Bruycker et al 2019). In the analyses we use the log of this count variable because we expect that the size of the effect of salience decreases as salience increases. ${ }^{3}$ Second, we understand complexity as the "degree to which a given policy problem is difficult to analyze, understand or solve" (Klüver 2013, p. 58), and we measure the complexity of a regulation by examining the readability of the proposal. Readability refers to the "ease of understanding or comprehension due to the style of writing" (Klare, 1963, p.1). Regulatory proposals of the Commission present the different aspects that a regulation is intended to address. In this case, the main assumption is that that the more technically demanding a regulation, the more difficult it will be in terms readability. We therefore used one of the most commonly used text readability measures of every policy proposal in our sample. More specifically, to measure complexity we rely on the Flesch Kincaid readability score (Kincaid et al., 1975), which is widely accepted and used in fields of medicine (Paasche-Orlow, Taylor and Brancati, 2003), education (Duffy and Kabance, 1982) as well as in business management (Wang, Hsieh and Sarkis 2018). ${ }^{4}$ The higher the value of the score, the more complex the regulation.

Regarding the institutional factors, we measured the effect of consultation arrangements on density and diversity by counting the number of different consultation tools employed by EU institutions to facilitate the dialogue and the engagement of stakeholders. We rely on an adapted version of the consultation tools listed by the European Commission Better Regulation Guidelines. ${ }^{5}$ Second, following recent research on interest group mobilization in the EU (e.g. Berkhout et al. 2015), we measure administrative capacities of the respective DirectoratesGenerals (DGs), which are responsible for each regulation. We focus on a particular aspect of administrative capacity, namely the human resources of institutions (see Bark and Bell 2019, for a similar approach). More specifically, we operationalized administrative capacity as the number of staff working in each DG (Berkhout et al. 2015). ${ }^{6}$ The final variable, "Administrative capacity", consists of the log of this variable. ${ }^{7}$

We add an organizational field factor as a control variable to examine the robustness of our regulation-specific and institutional factors. The key inter-organizational explanatory mechanism in the study of interest representation regarding the density (and diversity) of a stakeholder community is the so-called carrying capacity of a given domain or sector. That is, the number of viable politically active organizations can be largely predicted by the number of potential constituents within a given community (Berkhout et al 2015; Lowery et al 2005; Lowery and

3 - The time frame we use to collect articles ranges from two years before the first consultation tool was implemented up to 31st of December 2017. The outlets included in the Factiva search are: Financial Times, Politico Europe, Agence Europe, EurActive, EUObserver, and European Voice. For each regulation a search code was developed including key terms related to the regulation and general terms related to the EU decision making process. Subsequently, human coders went through the articles obtained via the Factiva search and excluded those that were not deemed as relevant. That is, only those that specifically discussed the regulation or the regulatory process leading to the regulation included in our sample were coded as relevant.

4 - Following Kincaid et al. (1975), the formula to obtain the readability scores reads as follows:

$0.39 *$ average sentence length $+11.8 *$ (number of syllables /number of words) -15.59 .

5 - see http://ec.europa.eu/smart-regulation/guidelines/tool_50_en.htm). These are: (1) open/public (online) consultation; (2) survey and questionnaire; (3) stakeholder conference/public hearings/events; (4) stakeholder meetings/workshops/seminars; (5) focus groups; (6) interviews; (7) commission expert groups/similar entities; (8) SME panels; (9) consultations of local/regional authorities (networks of the Committee of the Regions); (10) direct consultation of special stakeholder groups (including Member States); (11) others.

6 - For staff, see Human Resources Key Figures of the European Commission: https://ec.europa.eu/info/sites/info/ files/european-commission-hr-key-figures_2016_en.pdf.

7 - This log-transformation is justified by the presence of one outlier: DG Agriculture, whose budget includes subsidies to Members States and thus is significantly higher than the other DGs - it represents 38\% of the total budget. 
Gray 2016; Hanegraaff, Beyers, and Braun 2011). This leads us to expect that the number of potential constituents of a domain is positively related (but at a declining rate) to the number of mobilized stakeholders.

In order to measure the overall density of the included regulatory domains, or their carrying capacity, we needed a measure that validly captures the overall community of active stakeholders. In US research, for instance, such measures have been constructed by using (state or federal) lobby register data to count the overall number of mobilized stakeholders (Leech et al 2005; Lowery and Gray 1996). We used the Transparency Register, the register commissioned by both the EU Commission and the EU Parliament, which includes stakeholders who have been consulted by one of the EU institutions. ${ }^{8}$ The transparency register has been criticized for its reliability, given the voluntary nature of registrations. Yet its quality and inclusion of stakeholders has improved in recent years, rendering it useful for the purpose of academic research (Berkhout et al 2018; Greenwood and Dreger 2013). Our measure of the organizational field factor is constructed on the domain rather than the regulation or DG level to account for the effect of the wider interest community on regulation-specific mobilization. It is a count of the number of stakeholders for each of the six domains in our regulatory sample. We matched our policy domains with the different "fields of interest" distinguished in the Transparency Register (see Table A1 in the Appendix). We subsequently included the logged number of stakeholders registered in each domain to construct the measure of density, as we assume a decreasing effect size as the number of stakeholders increases (Klüver 2013, 120). Tables A2 and A3 in the Appendix present the descriptive statistics and the correlation coefficients of the variables included in our models.

\section{Analysis: the density and diversity of stakeholder engagement in eu regulatory governance}

We first assess the total number and type of stakeholders that were mobilized. This can be observed in Figure 1, which presents the distribution of stakeholders in the 47 regulations with stakeholder involvement. We relate the density of the mobilized actors to their overall diversity. Figure 1 shows a rather typical overall mobilization pattern that has also been observed in earlier studies of EU legislative politics (e.g. Wonka et al 2018), as well as research on stakeholder mobilization in different political systems at the national level (Baumgartner and Leech 2001, Halpin 2011). Yet, compared to previous studies, the pattern is considerably less skewed. For instance, Baumgartner and Leech, who examined lobbying patterns in the US on a random sample of 137 issues, found that the median issue attracted 15 groups, while 4 issues were characterized by lobbying of more than 500 groups. In our dataset, the median issue engaged 109 stakeholders, while we do not have strong outliers with very high levels of mobilization. Furthermore, whereas Baumgartner and Leech had many issues on which almost no rival groups were active, we do not have a long tail of regulations with very limited stakeholder mobilization. So, while the overall mobilization patterns follow a similar trend, there also appear typical characteristics of stakeholder engagement in regulatory governance. Compared to earlier work that also included policy measures that are not regulatory in nature, in our sample fewer issues are characterized by either high levels of conflict expansion or very low mobilization of stakeholders. At face value, Figure 1 also presents a clear correlation between density and the two diversity measures, indicating a positive relationship between density and diversity. At the same time, a correlation of .64 also indicates that this relationship is not as

8 - https://ec.europa.eu/info/about-european-commission/service-standards-and-principles/transparency/transparency-register_en 
straightforward as it might seem, as high density does not always result in high diversity and vice versa (see also Table A3 in the Appendix). This is an important argument for examining the factors driving density and diversity separately.

Figure 1: Stakeholder mobilization across regulations with consultations tools

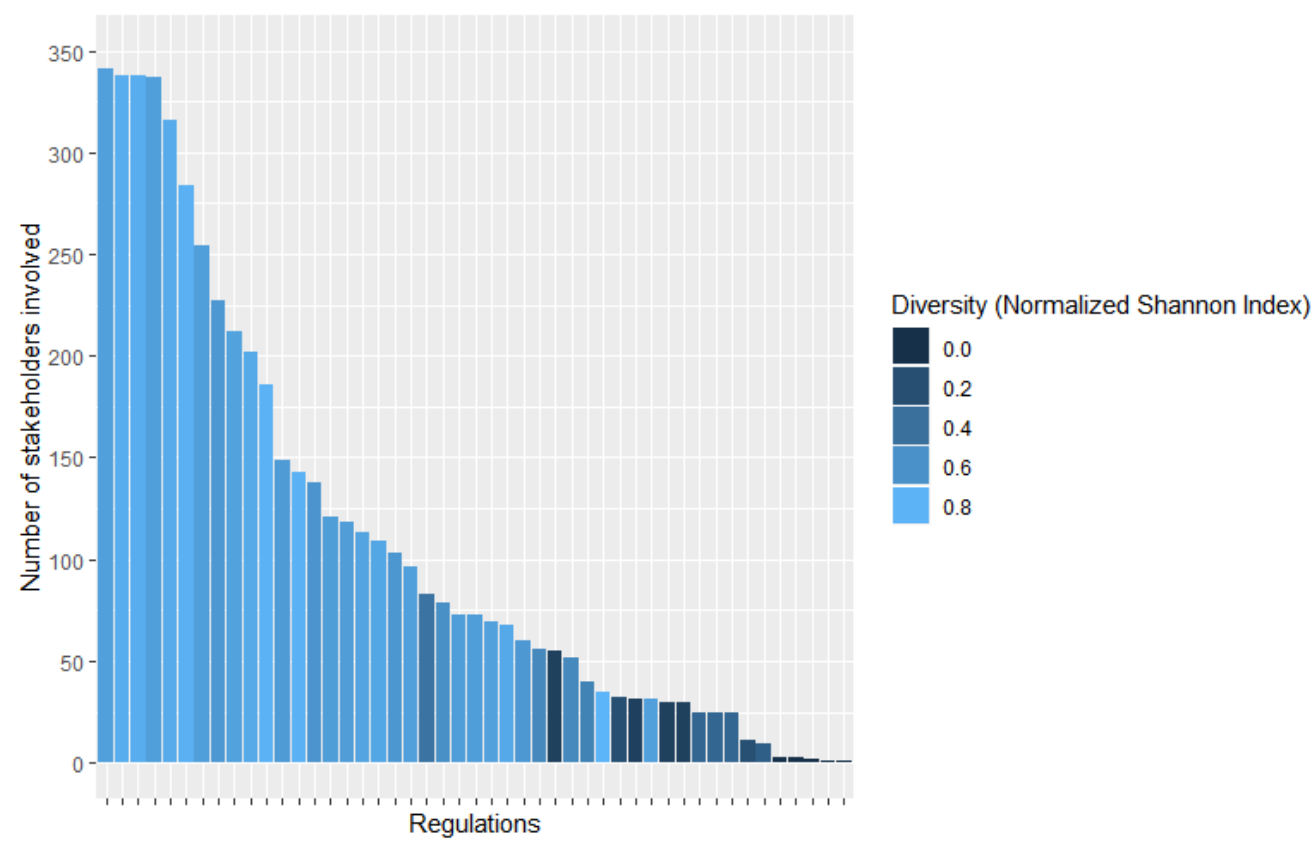

Source: The Authors

\section{Explaining the density and diversity of stakeholder engagement}

We ran several regression models to estimate the effect of the explanatory factors on density and diversity measures of our sampled regulations. Due to the small $n$, we discuss the results while comparing them with the bivariate relationship between the variables presented in the correlation matrix in Table A3 Tables 1 and 2 present three models for each dependent variable, the first two models (i.e., "a" and "b") only include regulation-specific and institutional factors, while in the third model (i.e., "c") we control for the organizational field factor. To analyze density, we opt for a negative binomial regression since our dependent variable is a count variable and highly skewed. We used a fractional regression model to analyze the effects of our factors on the diversity measure. This is an appropriate approach considering the distribution of both variables and the fact that they range between 0 and 1 and are measured as a proportion (Papke and Wooldridge 1996). In addition, we conducted variance inflation factor (VIF) test to control for possible multi-collinearity effects among our explanatory factors. Importantly, all the VIF values are below two, which is an acceptable value that indicates low correlation among the variables (see also Table A3 in the Appendix).

Table 1 presents the findings for the explanatory factors of density of stakeholder engagement at the regulation-level. First, model $1 \mathrm{a}$ indicates that more salient and complex regulations tend to have more stakeholders involved. Aligned with H1, the effect for salience is constant, even when controlling for institutional factors and for domain-level stakeholder density. Public 
visibility thus fosters stakeholder engagement. Regarding $\mathrm{H} 2$ on complexity, models $1 \mathrm{~b}$ and $1 c$ lead to a p-value close to 0.1 , thus our results should be interpreted with caution, also because our bivariate analyses do not present a significant relationship between complexity and density (see Table A3 in the Appendix). The positive coefficients indicate that more complex regulations require more input from a larger set of stakeholders. Regarding our second set of hypotheses on institutional factors, we first observe that the number of consultation tools implemented by public officials has a positive relationship with density. In addition, the significant and negative relationship between density and administrative capacity that is found in the correlation matrix (see Table A3) cannot be confirmed in our multivariate analyses as the pvalue of the negative estimates in model $1 \mathrm{c}$ is 0.374 . However, alternative operationalizations of administrative capacity, focusing on the absolute budget of the DGs instead of the staff, do lead to significant results (see Table A4 in the Appendix). Lastly, the supply-side factor, domain density, is negatively related to the level of density, yet the $p$-value is 0.129 , indicating a weak relationship between the variables. However, this negative association could indicate an explanatory effect of carrying capacity as it suggests that a higher density is related to fewer mobilized stakeholders.

Table 1: Assessing density of stakeholder engagement in regulatory governance

\begin{tabular}{|c|c|c|c|c|c|c|}
\hline & \multicolumn{2}{|l|}{ Model 1a } & \multicolumn{2}{|l|}{ Model 1b } & \multicolumn{2}{|l|}{ Model 1c } \\
\hline & Estimate & p-value & Estimate & $\mathrm{p}$-value & Estimate & $\mathrm{p}$-value \\
\hline Salience & $\begin{array}{l}0.367 \\
(0.104)\end{array}$ & $<.001$ & $\begin{array}{l}0.289 \\
(0.104)\end{array}$ & .005 & $\begin{array}{l}0.258 \\
(0.101)\end{array}$ & .011 \\
\hline Complexity & $\begin{array}{l}0.121 \\
(0.057)\end{array}$ & .034 & $\begin{array}{l}0.094 \\
(0.056)\end{array}$ & .092 & $\begin{array}{l}0.078 \\
(0.057)\end{array}$ & .167 \\
\hline $\begin{array}{l}\text { Consultation } \\
\text { tools }\end{array}$ & & & $\begin{array}{l}0.173 \\
(0.081)\end{array}$ & .034 & $\begin{array}{l}0.208 \\
(0.081)\end{array}$ & .010 \\
\hline $\begin{array}{l}\text { Administrative } \\
\text { capacity }\end{array}$ & & & $\begin{array}{l}-0.001 \\
(0.001)\end{array}$ & .285 & $\begin{array}{l}-0.0004 \\
(0.001)\end{array}$ & .374 \\
\hline $\begin{array}{l}\text { Density per } \\
\text { domain }\end{array}$ & & & & & $\begin{array}{l}-0.745 \\
(0.489)\end{array}$ & .127 \\
\hline Intercept & $\begin{array}{l}1.268 \\
(1.217)\end{array}$ & .297 & $\begin{array}{l}1.647 \\
(1.182)\end{array}$ & .163 & $\begin{array}{l}8.021 \\
(4.447)\end{array}$ & .071 \\
\hline AIC & 59.524 & & 63.118 & & 65.009 & \\
\hline $\begin{array}{l}\text { PseudoR2: } \\
\text { Nagelkerke }\end{array}$ & .346 & & .499 & & .544 & \\
\hline $\mathrm{N}$ & 47 & & 47 & & 47 & \\
\hline
\end{tabular}


In Table 2 we observe that salience and the number of consultation tools are the most important factors explaining stakeholder diversity, hence confirming $\mathrm{H} 1$ and $\mathrm{H} 3$. This means that the higher the salience of the regulation, the more diverse the set of stakeholders that gets involved. This aligns with previous findings (see Hanegraaff and Berkhout 2018) and confirms that a more diverse set of stakeholders gets mobilized on a regulation when it becomes more visible to the public. Regarding the institutional demand-side factors, only the number of consultation tools significantly affects the diversity of stakeholder engagement. In contrast to other studies, we do not find significant effects of the administrative capacity of the DG, suggesting that regulation-specific demand side factors are more important explanatory factors for diversity. Importantly, this non-significant relationship holds when operationalizing administrative capacity in terms of budget instead of staff (see Table A5 in the Appendix). Lastly, our supply-side variable (i.e., density per domain), is significantly and negatively related to the level of diversity of regulations.

Table 2: Assessing diversity of stakeholder engagement in regulatory governance

\begin{tabular}{|c|c|c|c|c|c|c|}
\hline & \multicolumn{2}{|l|}{ Model 1a } & \multicolumn{2}{|l|}{ Model 1b } & \multicolumn{2}{|l|}{ Model 1c } \\
\hline & Estimate & p-value & Estimate & $\mathrm{p}$-value & Estimate & p-value \\
\hline Salience & $\begin{array}{l}0.400 \\
(0.113)\end{array}$ & .001 & $\begin{array}{l}0.304 \\
(0.109)\end{array}$ & .007 & $\begin{array}{l}0.317 \\
(0.106)\end{array}$ & .004 \\
\hline Complexity & $\begin{array}{l}0.104 \\
(0.060)\end{array}$ & .094 & $\begin{array}{l}0.051 \\
(0.058)\end{array}$ & .381 & $\begin{array}{l}0.011 \\
(0.059)\end{array}$ & .846 \\
\hline $\begin{array}{l}\text { Consultation } \\
\text { tools }\end{array}$ & & & $\begin{array}{l}0.314 \\
(0.089)\end{array}$ & .001 & $\begin{array}{l}0.363 \\
(0.089)\end{array}$ & $<.001$ \\
\hline $\begin{array}{l}\text { Administrative } \\
\text { capacity }\end{array}$ & & & $\begin{array}{l}-0.0001 \\
(0.001)\end{array}$ & .728 & $\begin{array}{l}0.0004 \\
(0.001)\end{array}$ & .388 \\
\hline $\begin{array}{l}\text { Density per } \\
\text { domain }\end{array}$ & & & & & $\begin{array}{l}-1.220 \\
(0.517)\end{array}$ & .023 \\
\hline Intercept & $\begin{array}{l}-2.988 \\
(1.309)\end{array}$ & .027 & $\begin{array}{l}-2.878 \\
(1.254)\end{array}$ & .027 & $\begin{array}{l}6.858 \\
(4.654)\end{array}$ & .148 \\
\hline AIC & 18.204 & & 19.586 & & 20.691 & \\
\hline $\begin{array}{l}\text { PseudoR2: } \\
\text { Nagelkerke }\end{array}$ & .266 & & .440 & & .497 & \\
\hline $\mathrm{N}$ & 47 & & 47 & & 47 & \\
\hline
\end{tabular}

Source: The Authors

Overall, our findings suggest that regulation-specific and institutional factors affect the density and diversity of stakeholder engagement. Salience and the number of consultation tools seem to explain both density and diversity, but the complexity of the regulation seems to matter 
only for density and does not seem to be relevant for attracting more diverse set of stakeholders. In other words, highly technical regulations demand more input, but not necessarily from a diverse set of stakeholders. Another relevant difference relates to the effect of administrative capacity, which seems to matter for density - a negative relationship - but not for diversity.

\section{Robustness checks}

We ran several robustness checks. First, to examine whether our findings are applicable to regulatory processes without consultation arrangements we run $\mathrm{t}$-tests comparing the means of our two main regulation-specific variables (i.e., salience and complexity). The results are significant, suggesting that cases with formal consultation vary significantly from cases without formal consultation (cf. Van Ballaert 2017) in terms of salience and complexity. However, if we run models "a" and "b" to test our main hypotheses while including the full set of regulations, including those that did not have stakeholder involvement, we obtain similar results for density and diversity (see Table A6 and A7 in the Appendix). While the nature of the regulatory processes is different, it does not seem to affect our findings regarding the main explanatory factors of density and diversity. In addition, we conducted bootstrapping simulations as a resampling strategy to assess the robustness of our findings. The bootstrap resampling method included 1000 runs to compute confidence intervals around the observed coefficients of the regression models (see Table A8 in Appendix). Taken together, these robustness checks lend support to the analyses based on our sample of regulatory issues.

\section{Conclusion and discussion}

Stakeholder engagement has long been posited as a necessary component of regulatory governance and recent advancements in the literature specify different intermediary roles of stakeholders to engage with the regulatory process (Abbott et al 2017). As different numbers and types of stakeholders capable of engaging with the regulatory process will affect both the potential outcomes of stakeholder engagement as well as the intermediary roles stakeholders can fulfill, understanding the explanatory factors of the density and diversity of stakeholder engagement is warranted. Our findings indicate that the salience of a regulation and the number of different consultation tools employed by public institutions both affect the density and diversity of stakeholder engagement. The complexity of the regulation only seems to matter for the number of groups that get mobilized but is less relevant for explaining stakeholder diversity. In other words, highly technical regulations seemingly demand more input, but not necessarily from a diverse set of stakeholders. Another relevant difference between factors affecting density and diversity relates to the effect of administrative capacity, which seems to matter for density - negative relationship - but not for diversity. These are relevant findings as they point to the importance of regulation-specific explanatory factors for understanding and explaining both the number and type of stakeholders that engage with the regulatory process.

Before discussing the implications of our findings, it is important to consider the limitations of our study. We examined stakeholder engagement for a selected set of regulatory proposals in EU governance in a given time period and for a specific role in the regulatory process. Although the robustness checks lend support to the external validity of our analyses, further research into the regulation-specific explanatory factors of stakeholder engagement is required to confirm and further specify these findings. To further test effects of regulation-specific and institutional factors on stakeholder engagement, future research could include a larger sample of regulatory proposals over a longer period of time and across various stages in the regulatory process. In addition, by studying stakeholder engagement in EU regulatory governance, we se- 
lected a likely case of stakeholder engagement given its extensive consultation arrangements, providing us with the opportunity to empirically distinguish between regulatory-specific and institutional explanatory factors. Research demonstrates that such contextual factors matter for stakeholder engagement in general (Beyers et al 2015), including other institutional factors, such as the degree of neo-corporatism or pluralism, characterizing stakeholder engagement arrangements, or the type of lobby regulation in place (Chari et al 2019; but see Lowery and Gray 1997). We could not include these factors given our single case study of the EU as a most likely case of the regulatory state, but such contextual factors are obviously relevant to include, in addition to regulation-specific factors in future research into stakeholder engagement in regulatory governance at (supra)national and local levels of governance.

Notwithstanding these considerations, our findings have important implications for research on stakeholder engagement in (supra)national regulatory governance in particular and stakeholder engagement in policymaking more generally. As regards regulatory governance, the literature seems inconclusive about the potential impact of stakeholder engagement in (supranational) regulatory governance. Studies regarding regulatory enrolment (Black 2003), responsive regulation (Abbott and Snidal 2013), and the recently emerging literature on regulatory intermediaries (Abbott et al 2017; Brès et al 2019) all emphasize the potential of involving stakeholders in regulatory trajectories for effective and responsive regulatory governance, as well as the drawbacks of stakeholder engagement, most notably regulatory capture. Examining the explanatory factors of the number and type of stakeholder engagement helps to better specify the conditions under which such stakeholder arrangements are likely to yield positive outcomes or instead harm both the process and outcome of regulatory governance.

Our findings on stakeholder engagement also speak to stakeholder engagement beyond a mere focus on regulatory governance. While both salience and consultation tools relate to more diverse and denser stakeholder engagement, complexity of regulations results in bigger crowds, but not necessarily in more diverse engagement. These findings confirm the general finding that higher levels of government activity result in higher levels of stakeholder engagement, but not necessarily in more diverse stakeholder crowds. This can be explained by the complex interplay between the density and diversity of stakeholder communities (Lowery et al 2005; 2015; Lowery and Gray 2016) as well as by a positive relationship between higher levels of government activity and a narrowed and more specialized policy engagement of stakeholders (Halpin and Thomas 2012). Understanding how density and diversity relate to each other in the context of regulatory governance is one of the likely avenues for future research as well as a more explicit comparative perspective regarding stakeholder engagement in legislative and regulatory decision-making to specify the distinctive and common explanatory factors of stakeholder engagement across public decision-making processes.

In addition, our findings on the effect of consultation arrangements are in line with recent observations regarding the effect of the design of consultation arrangements (Arras and Braun 2017; Bunea 2017, Fraussen et al. 2020; Halpin and Fraussen 2017; Pedersen et al. 2015; Van Ballaert 2015; 2017) on the density and diversity of stakeholder engagement. As consultation is often regarded as an important instrument for better regulation, assessing how the institutional design and type of consultation arrangements affect both the density and diversity of stakeholder engagement, and the potential intermediary roles they can fulfill, is an important avenue for further research. 


\section{Bibliography}

Abbott, K.W., Levi-Faur, D., \& Snidal, D. (2017). Theorizing Regulatory Intermediaries, the RIT Model. The Annals of the Academy of Political and Social Science, 670(1), 14-35.

Abbott, K.W.; \& Snidal, D. (2013). Taking Responsive Regulation Transnational: Strategies for International Organizations. Regulation and Governance, 7, 95-113.

Ayres, I., \& Braithwaite, J. (1992). Responsive Regulation: Transcending the Deregulation Debate. New York: Oxford University Press.

Arras, S., \& Braun, C. (2017). Stakeholders Wanted! Why and How European Union Agencies Involve Non-state Stakeholders. Journal of European Public Policy, 25(9), 1257-1275. https://doi.org/10.1080/13501763.2017.1307438

Arras, S. (2017). European Union Agencies and Non-State Stakeholder Involvement. Why, how and what does it matter? PhD dissertation, University of Antwerp.

Baekgaard, M., Mortensen, P. B., \& Seeberg, H.B. (2018). The Bureaucracy and the Policy Agenda. Journal of Public Administration Research and Theory, 28(2), 239-253.

Bark, T., \& Bell, E. (2019). Issue Prioritization by Bureaucratic Leaders: The Influence of Institutional Structure.Administration\&Society,51(6), 915-950.https://doi.org/10.1177\%2F0095399718810194

Baumgartner, F.R., \& Leech, B.L. (2001). Interest Niches and Policy Bandwagons: Patterns of Interest Group Involvement in National Politics. Journal of Politics, 63(4), 1191-1213.

Baumgartner, F.R., Kimball, D.C., Berry, J.M., Hojnacki, M., \& Leech, B.L. (2009). Lobbying and Policy Change: Who wins, who loses and why. Chicago, IL: University of Chicago Press.

Baumgartner, F.R., \& Mahoney, C. (2008). The two faces of framing: individual-level framing and collective issue definition in the European Union. European Union Politics, 9(3), 435-449.

Berkhout, J., Carroll, B.J., Braun, C., Chalmers, A.W., Destrooper, T., Lowery, D., Otjes, S., \& Rasmussen, A. (2015). Interest Organizations Across Economic Sectors: Explaining Interest Group Density in the European Union. Journal of European Public Policy, 22(4): 462-480.

Berkhout, J., Hanegraaff, M., Beyers, J., Braun, C., \& Lowery, D. (2018). Making Inference across Mobilization and Influence Research: Comparing Top-Down and Bottom-Up Mapping of Interest Systems. Political Studies, 66(1), 43-62.

Berkhout, J., Hanegraaff, M., \& Braun, C. (2017). Is the EU different? Comparing the diversity of national and EU-level systems of interest organisations. West European Politics, 40(5), 1109-1131. https://doi.org/10.1080/01402382.2017.1308695

Berkhout, J., and Lowery, D. (2010). The Changing Demography of the EU Interest System Since 1990. European Union Politics, 11(3), 447-461.

Bernhagen, P. et al. (2016). INTEREURO Survey: Activities and Strategies of European Interest Groups: A Snapshot from the INTEREURO Survey. Stuttgart.

Beyers, J., and Arras, S. (2019). Who Feeds information to Regulators? Stakeholder Diversity in European Union Regulatory Agency Consultations. Journal of Public Policy, 1-26. https://doi.org/10.1017/s0143814x19000126

Beyers, J., Dür, A., \& Wonka, A. (2018). The Political Salience of EU Policies. Journal of European Public Policy, 25(11), 1726-1737. 
Beyers, J., Chaqués-Bonafont, L., Dür, A., Eising, R., Fink-Hafner, D., Lowery, D., Maloney, W., \& Naurin, D. (2014). The INTEREURO project: logic and structure. Interest Groups \& Advocacy, 3(2), 126-140.

Bingham, L.B., Nabatchi, T., and O'Leary, R. (2005). The New Governance: Practices and Processes For Stakeholder And Citizen Participation In The Work Of Government. Public Administration Review, 65(5), 547-558.

Black, J. (2003). Enrolling Actors in Regulatory Systems: Examples from UK Financial Services Regulation, Public Law, (Spring), p. 63-91.

Bouwen, P. (2004). Exchanging access goods for access: A comparative study of business lobbying in the European Union institutions. European Journal of Political Research, 43(3), 337-369.

Braun, C. (2012). The Captive or the Broker? Explaining Public Agency-Interest Group interactions. Governance: An International Journal of Policy, Administration, and Institutions, 25(2), 291-314.

Breunig, C., \& Koski, C. (2018). Interest groups and policy volatility, Governance, 31, 279-297.

Brès, L., Mena, S., \& Salles-Djelic, M-L. (2019). Exploring the Formal and Informal Roles of Regulatory Intermediaries in Transnational Multistakeholder Regulation. Regulation and Governance, 13, 127-140.

Broscheid, A., \& Coen, D. (2003). Insider and Outsider Lobbying of the European Commission: And Information Model of Forum Politics. European Union Politics, 4(2): 165-189.

Boydstun, A., Bevan, S., \& Thomas, H.F. (2014). The Importance of Attention Diversity and how to Measure it. Policy Studies Journal, 42(2), 173-196.

Bunea, A. (2017). Designing Stakeholder Consultations: Reinforcing or Alleviating Bias in the European Union System of Governance?, European Journal of Political Research, 56(1), 46-69.

Chari, R., Hogan, J., Murphy, G., \& Crepaz, M. (2019). Regulating Lobbying. A Global Perspective, Manchester: Manchester University Press.

Coen, D., and Katsaitis, A. (2013). Chameleon Pluralism in the EU: an Empirical Study of the European Commission Interest Group Density And Diversity Across Policy Domains. Journal of European Public Policy, 20(8), 1104-1119.

Coen, D., \& Katsaitis, A. (2017). Parliamentary Procedures \& Interest Group Mobilization: Evidence from the European Parliament Committees, EUI working paper, MWP 2017/6.

Coen, D., \& Richardson, J. (2009). Lobbying the European Union: Institutions, Actors and Issues. New York: Oxford University Press.

Coglianese, C., Zeckhauser, R. \& Parson, E. (2004). Seeking Truth for Power: Informational Strategy and Regulatory Policy Making. Minnesota Law Review, 109(89), 277-341.

Culpepper, P.D. (2010) Quiet Politics and Business Power. Corporate Control in Europe and Japan. Cambridge: Cambridge University Press.

De Bruycker, I., Berkhout, J., \& Hanegraaff, M. (2019). The Paradox of Collective Action: Linking Interest Aggregation and Interest Articulation in EU Legislative Lobbying. Governance, 32(2): 295312.

Duffy, T.M., \& Kabance, P. (1982). Testing a Readable Writing Approach to Text Revision. Journal of Educational Psychology, 74(5), 733-748.

Eising, R. (2007). The Access of Business Interests to EU Institutions: Towards Élite Pluralism? Journal of European Public Policy, 14(3), 384-403. 
European Commission. (2017). Better regulation “Toolbox”. Brussels: European Commission.

European Union (2007). Treaty of Lisbon amending the Treaty on European Union and the Treaty establishing the European Community, signed at Lisbon, 13 December 2007.

Fraussen, B., Albareda, A. \& Braun, C. (2020). Conceptualizing Consultation Approaches: Identifying Combinations of Consultation Tools and Analyzing their Implications for Stakeholder Diversity. Policy Sciences.

https://doi.org/10.1007/s11077-020-09382-3

Gray, V., \& Lowery, D. (1996). The Population Ecology of Interest Representation. Ann Arbor, MI: University of Michigan Press.

Gray, V., Lowery, D., \& Benz, J.K. (2013). Interest Groups and Health Care Reform across the United States. Washington, D.C.: Georgetown University Press.

Greenwood, J., \& Dreger, J. (2013). The Transparency Register: a European Vanguard of Strong Lobby Regulation? Interest Groups \& Advocacy, 2(2), 139-162.

Halpin, D. (2011). Explaining Policy Bandwagons: Organized Interest Mobilization and Cascades of Attention. Governance-an International Journal of Policy Administration and Institutions, 24(2), 205230.

Halpin, D. (2014). The Organization of Political Interest Groups: Designing Advocacy. Abingdon, UK: Routledge.

Halpin, D., \& Jordan, G. (2012). The Scale of Interest Organization in Democratic Politics: Data and Research Methods. New York, NY: Palgrave Macmillan.

Halpin, D., \& Fraussen. B. (2017). Conceptualising the Policy Engagement of Interest Groups: Involvement, Access and Prominence. European Journal of Political Research, 56, 723-732.

https://doi.org/10.1111/1475-6765.12194

Halpin, D., Fraussen, B., \& Nownes, A. (2018). The Balancing Act of Establishing a Policy Agenda: Conceptualizing and Measuring Drivers of Issue Prioritization Within Interest Groups. Governance, 31(2), 215-237.

Halpin, D., \& Thomas, H.F. (2012). Evaluating the Breadth of Policy Engagement by Organized Interests. Public Administration, 90(3), 582-599.

Hanegraaff, M., \& Berkhout, J. (2018). More Business as Usual? Explaining Business Bias Across Issues and Institutions in the European Union. Journal of European Public Policy, 26(6), 843-862. https://doi.org/10.1080/13501763.2018.1492006

Hanegraaff, M., Beyers, J., \& Braun, C. (2011). Open the Door to More of the Same? The Development of Interest Group Representation at the WTO. World Trade Review, 10(4), 447-472.

Hannan, M.T., \& Freeman, J. (1977). The Population Ecology of Organizations. The American Journal of Sociology, 82(5), 929-964.

Kincaid, J.P., Fishburne, R.P., Rogers, R.L., \& Chissom, B.S. (1975). Derivation of New Readability Formulas (Automated Readability Index, Fog Count and Flesch Reading Ease Formula) for Navy Enlisted Personnel. Naval Technical Training Command Millington TN Research Branch. RBR-8-75

Klare, G. (1963). The Measurement of Readability. Iowa: State University Press.

Klüver, H. (2013). Lobbying in the European Union. Interest Groups, Lobbying Coalitions, and Policy Change. Oxford, UK: Oxford University Press. 
Klüver, H., \& Zeidler, E. (2018). Explaining Interest Group Density Across Economic Sectors: Evidence from Germany. Political Studies, 67(2), 459-478.

Klüver, H., Braun, C., \& Beyers, J. (2015). Legislative Lobbying in Context: Towards a Conceptual Framework of Interest Group Lobbying in the European Union. Journal of European Public Policy, 22(4), 447-461.

Koop, C., \& Lodge, M. (2017). What is Regulation? An Interdisciplinary Concept Analysis. Regulation \& Governance, 11, 95-108.

Leech, B.L., Baumgartner, F.R., La Pira, T.M., \& Semanko, N.A. (2005). Drawing Lobbyists to Washinghton: Government Activity and the Demand for Advocacy. Political Research Quarterly, 58(1), 19-30.

Lowery, D., \& Gray, V. (2016), On the Political Origins of the Bias in the Heavenly Chorus. Interest Groups \& Advocacy, 5(1), 25-56.

Lowery, D., \& Gray, V. (2004). A Neopluralist Perspective on Research on Organized Interests. Political Research Quarterly, 57(1), 163-175.

Lowery, D., \& Gray, V. (1997). How Some Rules Just Don't Matter: The Regulation of Lobbyists, Public Choice, 91(2), 139-147.

Lowery, D. \& Gray, V. (1996). The Population Ecology of Interest Representation: Lobbying communities in the American States. Michigan: University of Michigan Press.

Lowery, D., Gray, V., \& Halpin, D. (2015). The Organization Ecology of Interest Communities. Assessment and Agenda. London: Palgrave MacMillan.

Lowery, D., Gray, V., \& Fellowes, M. (2005). Sisyphus Meets the Borg. Economic Scale and Inequalities in Interest Representation. Journal of Theoretical Politics, 17(1), 41-74.

Lowery, D., Gray, V., Fellowes, M., \& Anderson, J. (2004). Living in the Moment: Lags, Leads, and the Link between Legislative Agendas and Interest Advocacy. Social Science Quarterly, 85(2): 463-477.

Majone, G. (1997). From the Positive to the Regulatory State: Causes and Consequences of Changes in the Mode of Governance. Journal of Public Policy, 17(2), 139-167.

Martinez, M. G., Verbruggen, P. \& Fearne, A. (2013). Risk-Based Approaches To Food Safety Regulation: What Role for Co-Regulation?, Journal of Risk Research, 16(9), 1101-1121.

Messer, A., Berkhout, J., \& Lowery, D. (2011). The Density of the EU Interest System: A Test of the ESA Model. British Journal of Political Science, 41(1), 161-190.

Minkoff, D., Aisenbrey, S., \& Agnone, J. (2008). Organizational Diversity in the US Advocacy Sector. Social Problems, 55(4), 525-548.

https://doi.org/10.1525/sp.2008.55.4.525

OECD (2016), Best Practice Principles on Stakeholder Engagement in Regulatory Policy, Draft for Public Consultations. Paris: OECD.

OECD (2012). Recommendation of the Council on Regulatory Policy and Governance. Paris: OECD.

OECD (2003). Institutional Capacity and Climate Actions. Paris: OECD.

Paasche-Orlow M.K., Taylor H.A., \& Brancati F.L. (2003). Readability Standards for Informed-Consent Forms as Compared with Actual Readability. The New England Journal of Medicine, 348(8), 721726. 
Pagliari, S., \& Young, K. (2016). The Interest Ecology of Financial Regulation: Interest Group Plurality in the Design of Financial Regulatory Policies. Socio-Economic Review, 14(2), 309-337. http://dx.doi.org/10.1093/ser/mwv024

Papke, L., \& Wooldridge, J.M. (1996). Econometric Methods for Fractional Response Variables With an Application to 401 ( K) Plan Participation Rates. Journal of Applied Econometrics 11(6), 619-632.

Pedersen, H., Halpin, D., \& Rasmussen, A. (2015). Who Gives Evidence to Parliamentary Committees? A Comparative Investigation of Parliamentary Committees and their Constituencies. The Journal of Legislative Studies, 21(3), 408-427.

https://doi.org/10.1080/13572334.2015.1042292

Princen, S., \& Kerremans, B. (2008). Opportunity Structures in the EU Multilevel System. West European Politics, 31(6), 1129-1146.

Rasmussen, A., \& Carroll, B.J. (2014). Determinants of Upper-Class Dominance in the Heavenly Chorus: Lessons from European Union Online Consultations. British Journal of Political Science, 44, 445-459.

Schattschneider, E.E. (1960). The Semisovereign People: A Realist's View of Democracy in America, New York, NY: Holt, Rinehart, and Winston.

Thomson, A.M., \& Perry, J.L. (2006). Collaboration Processes: Inside the Black Box. Public Administration Review, 66, 20-32.

Van Ballaert, B. (2017). The European Commission's Use of Consultation During Policy Formulation: The Effects of Policy Characteristics. European Union Politics, 18(3), 406-423.

https://doi.org/10.1177\%2F1465116517702004

Van Ballaert, B. (2015). The Politics behind the Consultation of Expert Groups: An Instrument to Reduce Uncertainty or to Offset Salience? Politics and Governance, 3(1), 139-150.

Verbruggen, P. (2013). Gorillas in the closet? Public and Private Actors in the Enforcement of Transnational Private Regulation. Regulation and Governance, 7(4), 512-532.

Wang, Z., Hsieh, T.S., \& Sarkis, J. (2018). CSR Performance and the Readability of CSR Reports: Too Good to be True? Corporate Social Responsibility and Environmental Management, 25(1): 66-79.

Wonka, A., Baumgartner, F.R., Mahoney, C. \& Berkhout, J. (2010). Measuring the size and scope of the EU interest group population. Journal of European Union Politics, 11(3): 463-476

Wonka, A., De Bruycker, I., De Bièvre, D., Braun, C., \& Beyers, J. (2018). Patterns of Conflict and Mobilization: Mapping Interest Group Activity in EU Legislative Policymaking. Politics and Governance, 6(3), 136-146. 


\section{Appendix}

Table A1. Match between policy domains and fields of interest of the Transparency Register

\begin{tabular}{|c|c|}
\hline Policy domains & Fields of interest in the Transparency Register \\
\hline \multirow{2}{*}{ Finance, banking, pensions, securities, insurances } & Banking and financial services \\
\hline & Economy, Finance, and the Euro \\
\hline \multirow{4}{*}{ State aids, commercial policies } & Competition \\
\hline & Business and Industry \\
\hline & Taxation \\
\hline & Trade \\
\hline Health & Public Health \\
\hline \multirow{3}{*}{ Sustainability, energy, environment } & Climate Action \\
\hline & Energy \\
\hline & Environment \\
\hline \multirow{3}{*}{ Transport, telecommunications } & Transport \\
\hline & Communications \\
\hline & Trans-European Networks \\
\hline Agriculture and fisheries & $\begin{array}{l}\text { Agriculture } \\
\text { Maritime affairs and fisheries }\end{array}$ \\
\hline
\end{tabular}

Source: The Authors

Table A2. Descriptive statistics of dependent and independent variables across regulations ( $n=47)$

\begin{tabular}{|c|c|c|c|}
\hline Variable & Measurement & Mean (S.D.) & Min-Max \\
\hline \multicolumn{4}{|l|}{ Dependent variables } \\
\hline Density & Number of skateholders per regulation & $109.1(104.779)$ & $1-341$ \\
\hline Diversity & Shannon-H Index & $.505(.27)$ & $0-.804$ \\
\hline \multicolumn{4}{|c|}{ Explanatory factors: Demand-side variables } \\
\hline \multicolumn{4}{|c|}{ Regulation-specific characteristics } \\
\hline Salience & $\begin{array}{l}\text { Logged number of articles published that } \\
\text { were related to the regulation }\end{array}$ & $2.145(1.364)$ & $0-4.553$ \\
\hline Complexity & Flesch Kincaid readability score & $20.640(2.481)$ & $16.909-30.350$ \\
\hline \multicolumn{4}{|l|}{ Institutional-demand } \\
\hline Consultation tools & Number of consultation tools used & $2.251(2.152)$ & $0-8$ \\
\hline Administrative capacity & Number of staff per DG & $591.043(267.602)$ & $159-1024$ \\
\hline \multicolumn{4}{|c|}{ Control factor: Supply-side variables } \\
\hline Density per domain & $\begin{array}{l}\text { Logged number of interest groups in } \\
\text { each domain }\end{array}$ & $3950(1221.704)$ & $2548-5657$ \\
\hline
\end{tabular}


Table A3. Correlation matrix of dependent and independent variables $(n=47)$

\begin{tabular}{lccccccc}
\hline & 1 & 2 & 3 & 4 & 5 & 6 & 7 \\
\hline 1.Density & 1 & & & & & & \\
2.Diversity & $0.646^{* * *}$ & 1 & & & & & \\
3.Salience & $0.451^{* *}$ & $0.470^{* * *}$ & 1 & & & & \\
4.Complexity & 0.215 & 0.205 & -0.043 & 1 & & & \\
5.Consultation tools & $0.484^{* * *}$ & $0.581^{* * *}$ & $0.290^{*}$ & $0.254^{*}$ & 1 & & \\
6.Administrative capacity & $-0.0309^{*}$ & -0.027 & -0.166 & 0.053 & -0.040 & 1 & \\
7.Density per domain & -0.199 & -0.191 & 0.014 & -0.233 & 0.119 & 0.170 & 1 \\
\hline
\end{tabular}

$+\mathrm{p} \leq .1 ;{ }^{*} \mathrm{p} \leq .05 ;{ }^{* *} \mathrm{p} \leq .01 ;{ }^{* * *} \mathrm{p} \leq .001$

Source: The Authors

Table A5. Assessing density of stakeholder engagement in regulatory governance

\begin{tabular}{|c|c|c|c|c|}
\hline & \multicolumn{2}{|l|}{ Model 1} & \multicolumn{2}{|l|}{ Model 2} \\
\hline & Estimate & p-value & Estimate & $\mathrm{p}$-value \\
\hline Salience & $0.319(0.104)$ & .002 & $0.272(0.098)$ & .006 \\
\hline Complexity & $0.097(0.057)$ & .090 & $0.088(0.056)$ & .113 \\
\hline Consultation tools & $0.164(0.083)$ & .049 & $0.202(0.080)$ & .012 \\
\hline $\begin{array}{l}\text { Administrative capacity (DG } \\
\text { budget logged) }\end{array}$ & $-0.075(0.104)$ & .468 & $-0.168(0.101)$ & .094 \\
\hline Density per domain & & & $-1.096(0.481)$ & .023 \\
\hline Intercept & $1.764(1.274)$ & .166 & $9.831(4.455)$ & .011 \\
\hline AIC & \multicolumn{2}{|l|}{63.152} & \multicolumn{2}{|l|}{64.919} \\
\hline PseudoR2: Nagelkerke & \multicolumn{2}{|l|}{.475} & \multicolumn{2}{|l|}{.576} \\
\hline $\mathrm{N}$ & \multicolumn{2}{|l|}{47} & \multicolumn{2}{|l|}{47} \\
\hline
\end{tabular}

Source: The Authors

9 - For budget, see Consolidated annual accounts of the EU of 2015, page 127: http://ec.europa.eu/budget/library/ biblio/documents/2015/EU_AnnualAccounts2015_EN.pdf.

This log-transformation is justified by the presence of one outlier: DG Agriculture, whose budget includes subsidies to Members States and thus is significantly higher than the other DGs - it represents $38 \%$ of the total budget. 
Table A5. Assessing density of stakeholder engagement in regulatory governance

\begin{tabular}{|c|c|c|c|c|}
\hline & \multicolumn{2}{|l|}{ Model 1} & \multicolumn{2}{|l|}{ Model 2} \\
\hline & Estimate & p-value & Estimate & $\mathrm{p}$-value \\
\hline Salience & $0.297(0.107)$ & .008 & $0.301(0.106)$ & .007 \\
\hline Complexity & $0.045(0.058)$ & .439 & $0.015(0.059)$ & .803 \\
\hline Consultation tools & $0.324(0.090)$ & $>.001$ & $0.362(0.090)$ & $<.001$ \\
\hline $\begin{array}{l}\text { Administrative capacity (DG } \\
\text { budget logged) }\end{array}$ & $0.077(0.108)$ & .480 & $0.038(0.108)$ & .727 \\
\hline Density per domain & & & $-1.089(0.511)$ & .039 \\
\hline Intercept & $-3.199(1.356)$ & .023 & $6.584(4.754)$ & .173 \\
\hline $\mathrm{AIC}$ & 19.512 & & 20.677 & \\
\hline PseudoR2: Nagelkerke & .445 & & .498 & \\
\hline $\mathrm{N}$ & 47 & & 47 & \\
\hline
\end{tabular}

Source: The Authors

Table A6. Assessing density of stakeholder engagement in regulatory governance

\begin{tabular}{|l|l|l|l|l|}
\hline & \multicolumn{2}{|l|}{ Model 1a } & \multicolumn{2}{l}{ Model 1b } \\
\hline & Estimate & p-value & Estimate & p-value \\
\hline Salience & $0.458(0.159)$ & 0.004 & $0.304(0.131)$ & 0.021 \\
\hline Complexity & $0.245(0.092)$ & 0.008 & $0.130(0.077)$ & 0.098 \\
\hline Consultation tools & & & $2.537(0.274)$ & $<0.001$ \\
\hline Administrative capacity & & & $-0.001(0.001)$ & 0.391 \\
\hline Intercept & $-1.771(1.906)$ & 0.353 & $-2.61433 \quad 1.51$ & 0.085 \\
\hline AIC & 80.086 & & 82.109 & \\
\hline PseudoR2: Nagelkerke & 0.240 & 64 & 0.751 & \\
\hline N & 64 & 64 & \\
\hline
\end{tabular}

Source: The Authors 
Table A7. Assessing diversity of stakeholder engagement in regulatory governance

\begin{tabular}{|l|l|l|l|l|}
\hline & \multicolumn{2}{|l|}{ Model 2a } & \multicolumn{2}{l}{ Model 2b } \\
\hline & Estimate & p-value & Estimate & p-value \\
\hline Salience & $0.481(0.128)$ & $<0.001$ & $0.289(0.116)$ & 0.015 \\
\hline Complexity & $0.227(0.073)$ & 0.003 & $0.065(0.064)$ & 0.319 \\
\hline Consultation tools & & & $0.548(0.087)$ & $<0.001$ \\
\hline Administrative capacity & & & $0.000(0.001)$ & 0.646 \\
\hline Intercept & $-6.14530 \quad 1.559$ & $<0.001$ & $-4.119(1.366)$ & 0.003 \\
\hline AIC & 32.165 & & 24.640 & \\
\hline PseudoR2: Nagelkerke & 0.312 & 0.650 & \\
\hline N & 64 & 64 & \\
\hline
\end{tabular}

Source: The Authors

Table A8. Confidence intervals based on bootstrap simulations ${ }^{10}$

Assessing density of stakeholder engagement in regulatory governance Model 1a Model 1b

Model 1c

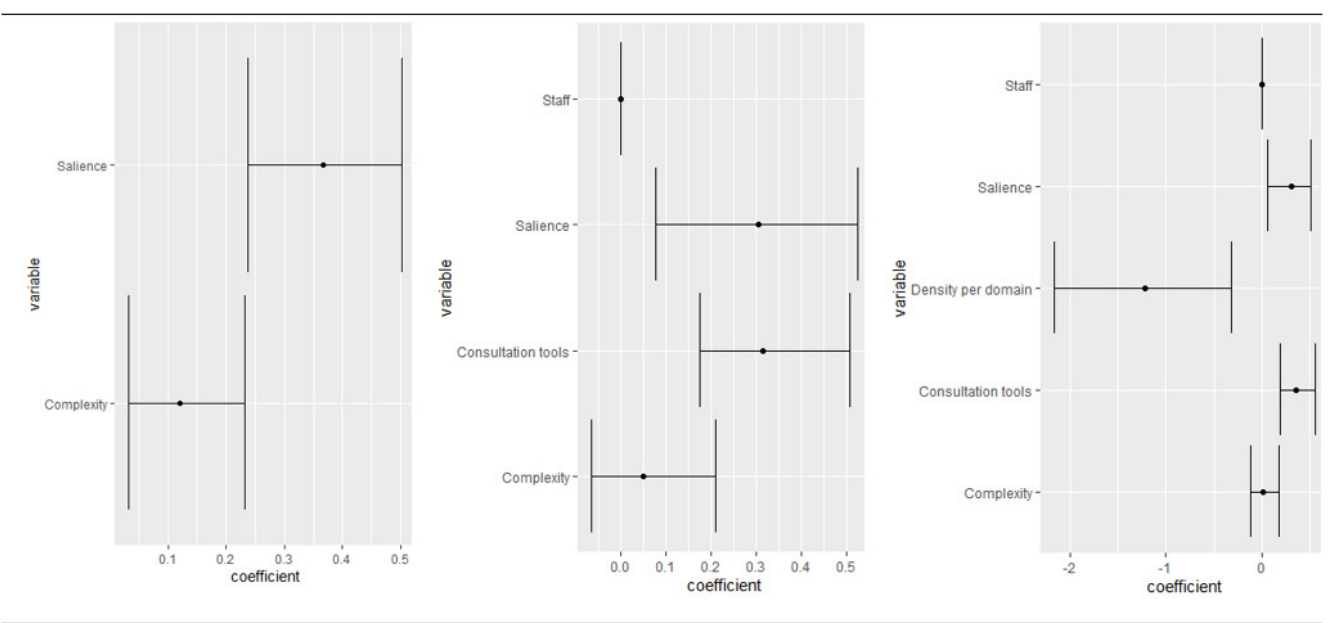

10 - We ran bootstrap simulations for each of the models to calculate confidence intervals for the coefficients (1000 runs each). The table below presents the bootstrapped confidence intervals around the coefficients attained through running the various regression models (90\% confidence intervals). 


\section{Assessing diversity of stakeholder engagement in regulatory governance}

Model 2a

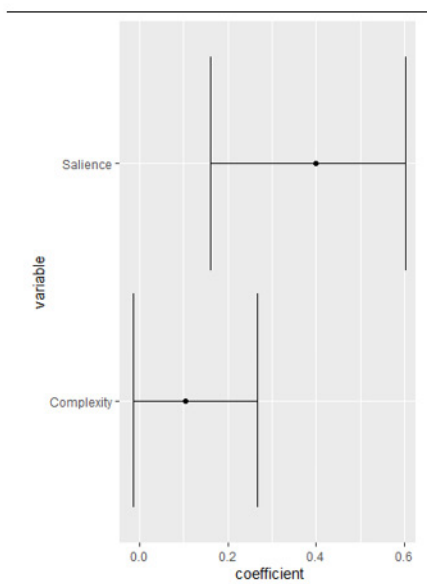

Model 2b

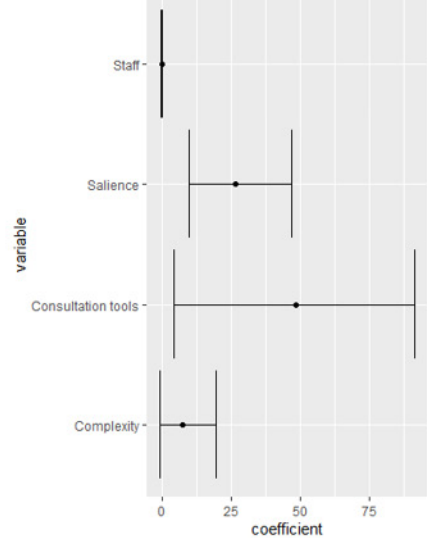

Model 2c

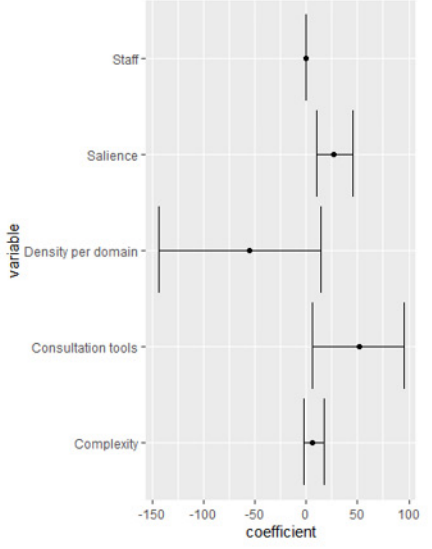

